\title{
EDITORIAL
}

\section{Management of work-related asthma: guidelines and challenges}

\author{
Barbara Legiest and Benoit Nemery
}

$\mathbf{A}$ sthma is one of the most common chronic diseases in working populations. Overall, $\sim 15 \%$ of all adult-onset asthma is estimated to be caused by occupational exposure to a respiratory sensitiser or irritant [1-3]. Although occupational asthma is probably the most frequently reported respiratory disorder in varying occupations [4,5], the disease is still underdiagnosed. Systematic research on incidence rates, health impact and socioeconomic burden of occupational asthma is sparse and national estimates are difficult to compare [5-7]. Work-related asthma imposes a significant financial cost that is mainly borne by affected employees and government $[8,9]$. On top of physical impairment, the patient faces problems regarding employment [10] and other psychosocial problems [11]. However, proper management is not expensive [12] and even a low reduction in disease burden would be cost effective [13]. Moreover, prevention management towards occupational asthma influences the health impact of diseases with overlapping risk factors, such as chronic obstructive pulmonary disease.

Work-related asthma covers occupational asthma and work aggravated/exacerbated asthma. Occupational asthma includes asthma caused by (allergic) sensitisation to a workplace agent, with sensitisation occurring during an asymptomatic latency period via immunoglobulin (Ig)E-mediated mechanisms or other hitherto largely unknown mechanisms, and irritantinduced asthma which occurs without evidence of sensitisation to the offending agent [14]. The clinical course of immunological occupational asthma with latency period does not differ from non-occupational allergic asthma, where a low amount of allergen is sufficient to provoke symptoms and where an evolution towards persistent "nonspecific" asthma is possible if exposure persists. This clinical course and the high prevalence of occupational asthma underscore the need to invest further in the challenging prevention of occupational asthma at both the individual and population level [3].

This issue of the European Respiratory Review (ERR) contains five articles written by members of a European Respiratory Society (ERS) Task Force on the Management of Work-related Asthma. Its conclusions have been published in the European

Dept of Public Health, Occupational and Environmental insurance Medicine, KU Leuven, Leuven, Belgium.

CORRESPONDENCE: B. Nemery, Research Unit of Lung Toxicology, Herestraat 49 (706), Leuven B-3000, Belgium. E-mail: Ben.Nemery@med.kuleuven.be

PROVENANCE: Submitted article, peer reviewed.
Respiratory Journal [15], but the ERR is to be congratulated for publishing the extensive material that has led to these conclusions. Such comprehensive material will be useful for interested respiratory or occupational medicine specialists, and also for government regulators and other decision makers responsible for the prevention of occupational diseases. The merit of these chapters rests not only in their detailed content but, perhaps even more, in providing a detailed description of the process that led to the conclusions.

The panel of experts tried to give answers to specific questions implicating all the steps in the hierarchy of control measures, and aimed to contribute to the standardisation and harmonisation of the preventative management of occupational asthma. To do so, relevant articles were selected from the published medical literature. Following this, selected relevant articles were systematically reviewed and evidence rated [16]. The strength of the evidence for the statements is based on the quality and quantity of the evidence (Royal College of General Practitioners) and the resulting recommendations are classified according to strength of evidence and clinical relevance [17]. This transparent process makes it possible for occupational health professionals to pragmatically interpret the recommendations in practice.

The ERS recommendations generally confirm and expand on the existing guidelines for the management of work-related asthma from the Agency for Healthcare Research and Quality, the British Occupational Health Research Foundation and the American College of Chest Physicians [18-20]. The classical hierarchical approach of primary prevention is also applicable to occupational asthma. Elimination of exposure is the best approach to prevent the occurrence of occupational asthma. Since elimination is not always possible, exposure reduction is the next best option towards primary preventive action. Medical surveillance should be performed in workers at risk, defined by work environment and individual risk factors identified by a questionnaire. Early recognition and diagnosis is recommended because longer symptomatic exposure relates to a worse outcome of occupational asthma. Recognition and diagnosis can be achieved by using consecutive diagnostic tests with independent and additional predictive values [21]. Comprehensive medical surveillance is followed by intervention steps directed towards the employee at risk and colleagues. After diagnosis, avoidance of exposure to the causal agent is the first-choice strategy. Reduction of exposure is another possible option, although with a lower likelihood of symptomatic improvement and recovery, but with less income loss and unemployment. The 
use of respiratory protection equipment alone is not considered sufficiently safe, especially in the long term.

This approach of formulating and grading recommendations has clearly identified the knowledge gaps and bottlenecks in preventative measures and indicates the need for improved management and the following priorities for experimental and epidemiological research [15]. Intensity of exposure is the dominant determinant in the development of occupational asthma and an exposure-response relationship has been demonstrated for some high- and low-molecular weight agents between exposure intensity and IgE-mediated sensitisation or work-related respiratory symptoms [22, 23]. However, for most respiratory sensitisers (especially low-molecular weight) more standardised quantifications are required to calculate reliable health-based occupational exposure standards [24-27]. Stumbling blocks are individual susceptibility, concomitant exposures, cross reactivity, erratic pattern of the exposure levels [28] and, additionally, technical limitations [24, 27]. It is not practically realistic to define specific thresholds for such a large number of agents. A provocative consideration may be that tolerance is more readily achieved when there is a constant low-dose exposure than when there is minimal time-weighted average exposure but occasional high peaks.

Prudence regarding dermal exposure to asthmagens is also advised [29]. Animal studies have demonstrated that dermal exposure to sensitisers can elicit respiratory inflammation after airway challenge [30]. Case reports and limited epidemiological studies (primarily isocyanates) support this concept [31]. Moreover, several common occupational contact allergens can also potentially cause occupational asthma [32]. Methodology for measuring skin exposure should be developed further, and skin exposure assessment should be more integrated in the risk management for occupational asthma [26].

The importance of early diagnosis of occupational asthma has been highlighted. When studying the delaying factors in the diagnostic course [9, 33-35], starting symptomatic asthma therapy without being aware of the causal link with occupational exposure is one of the main reasons of delay [36, 37]. In this respect, the availability of effective medication for the control of asthma often results in the fact that physicians do not sufficiently look for an occupational (or other) aetiology in their asthmatic patients! Medical surveillance (through occupational health services) can play a central role in shortening the diagnostic course. However, when the immunological mechanisms are still unclear, early disease markers are difficult to identify [38]. Periodic screening and monitoring are, therefore, generally limited to the detection of risk factors and initial clinical symptoms. This underscores that a better understanding of the pathophysiological mechanisms of occupational asthma is necessary in order to provide tools for early diagnosis, prevention and therapy.

The first step in a risk analysis is the identification of the substances capable of causing occupational asthma [39, 40]. One aim of future research should be to develop validated screening methods to identify potential asthmagens before they enter in the workplace [41-44]. With the current deficient hazard identification, occupational physicians must remain vigilant as novel chemicals or processes may cause unexpected disease, including occupational asthma.
There is moderate evidence about the effectiveness of medical intervention programmes [45]. The evaluation of preventive intervention measures is limited by lack of quantitative assessment of the exposure (reduction) and by difficult estimation of the intended health gain [46] due to reduced exposure, especially for chronic diseases with latency period. The indirect evidence for medical surveillance calls for prospective studies [47].

Currently, the guidelines pertain to all the components of occupational asthma and no clear distinction has been made between the different agents. Nevertheless, characteristics of the sensitising agents do determine some clinical and immunological features based on different pathogenic mechanisms [48]. Defining the risk factors and reviewing the intervention options are based on an unequal distribution between studies describing high- and low-molecular weight-induced asthma. The mechanisms of irritant-induced asthma remain largely unknown [26]. Asthma caused by acute high irritant exposure (reactive airways dysfunction syndrome) is well recognised. However, asthma occurring after latency, following repeated low-to-moderate exposure to irritants, is still controversial. Nevertheless, the excess risk of asthma in occupations with chronic low level irritant exposures is increasingly being reported $[26,49,50]$ and, according to the Shield reporting system (Midland Thoracic Society surveillance Scheme of Occupational Asthma in the UK), a small but substantial proportion of occupational asthma can be defined as irritant-induced asthma with latency [51]. Therefore, more attention should be given to the effects of low-to-moderate exposure to irritants. Irritant-induced asthma with latency is clinically difficult, if not impossible, to distinguish from immunological occupational asthma, and some agents are known to have toxic and allergic properties [52]. Experimental studies investigating different sensitising and irritant asthmagens will hopefully provide the basis for improving and refining the management guidelines.

\section{STATEMENT OF INTEREST}

None declared.

\section{REFERENCES}

1 Balmes J, Becklake M, Blanc P, et al. American Thoracic Society Statement: occupational contribution to the burden of airway disease. Am J Respir Crit Care Med 2003; 167: 787-797.

2 Kogevinas M, Zock JP, Jarvis D, et al. Exposure to substances in the workplace and new-onset asthma: an international prospective population-based study (ECRHS-II). Lancet 2007; 370: 336-341.

3 Toren K, Blanc PD. Asthma caused by occupational exposures is common - a systematic analysis of estimates of the populationattributable fraction. BMC Pulm Med 2009; 9: 7.

4 Jaakkola MS, Piipari R, Jaakkola N, et al. Environmental tobacco smoke and adult-onset asthma: a population-based incident casecontrol study. Am J Public Health 2003; 93: 2055-2060.

5 van Kampen V, Merget R, Butz M, et al. Trends in suspected and recognized occupational respiratory diseases in Germany between 1970 and 2005. Am J Ind Med 2008; 51: 492-502.

6 Jaakkola MS, Jaakkola JJ. Assessment of public health impact of work-related asthma. BMC Med Res Methodol 2012; 12: 22.

7 Karjalainen A, Kurppa K, Virtanen S, et al. Incidence of occupational asthma by occupation and industry in Finland. Am J Ind Med 2000; 37: 451-458. 
8 Ayres JG, Boyd R, Cowie $\mathrm{H}$, et al. Costs of occupational asthma in the UK. Thorax 2011; 66: 128-133.

9 Fishwick D, Bradshaw L, Davies J, et al. Are we failing workers with symptoms suggestive of occupational asthma? Prim Care Respir J 2007; 16: 304-310.

10 Larbanois A, Jamart J, Delwiche JP, et al. Socioeconomic outcome of subjects experiencing asthma symptoms at work. Eur Respir J 2002; 19: 1107-1113.

11 Miedinger D, Lavoie KL, L'Archeveque J, et al. Quality-of-life, psychological, and cost outcomes 2 years after diagnosis of occupational asthma. J Occup Environ Med 2011; 53: 231-238.

12 Baur X, Sigsgaard T. The new guidelines for management of workrelated asthma. Eur Respir J 2012; 39: 518-519.

13 Meijster T, Warren N, Heederik D, et al. What is the best strategy to reduce the burden of occupational asthma and allergy in bakers? Occup Environ Med 2011; 68: 176-182.

14 Baur X, Aasen TB, Burge PS, et al. The management of workrelated asthma guidelines: a broader perspective. Eur Respir Rev 2012; 21: 125-139.

15 Baur X, Sigsgaard T, Aasen TB, et al. Guidelines for the management of work-related asthma. Eur Respir J 2012; 39: 529-545.

16 Harbour R, Miller J. A new system for grading recommendations in evidence based guidelines. BMJ 2001; 323: 334-336.

17 Guyatt GH, Oxman AD, Vist GE, et al. GRADE: an emerging consensus on rating quality of evidence and strength of recommendations. BMJ 2008; 336: 924-926.

18 Beach J, Rowe BH, Blitz S, et al. Diagnosis and management of workrelated asthma. Evid Rep Technol Assess (Summ) 2005; 129: 1-8.

19 Nicholson PJ, Cullinan P, Burge PS, et al. Occupational Asthma: Prevention, Identification and Management: Systematic Review and Recommendations. London, British Occupational Health Research Foundation, 2010.

20 Tarlo SM, Balmes J, Balkissoon R, et al. Diagnosis and management of work-related asthma: American College of Chest Physicians Consensus Statement. Chest 2008; 134: Suppl. 3, 1S-41S.

21 Schlünssen V, Meijer E, Henneberger PK. Prevention of workrelated asthma seen from the workplace and the public health perspective. In: Sigsgaard T, Heederik D, eds. Occupational Asthma. Heidelberg, Springer Verlag, 2010; pp. 281-298.

22 Jones MG. Exposure-response in occupational allergy. Curr Opin Allergy Clin Immunol 2008; 8: 110-114.

23 Vandenplas O. Occupational asthma: etiologies and risk factors. Allergy Asthma Immunol Res 2011; 3: 157-167.

24 Bello D, Woskie SR, Streicher RP, et al. Polyisocyanates in occupational environments: a critical review of exposure limits and metrics. Am J Ind Med 2004; 46: 480-491.

25 Fernandez-Nieto M, Quirce S, Sastre J. Occupational asthma in industry. Allergol Immunopathol (Madr) 2006; 34: 212-223.

26 Maestrelli P, Boschetto P, Fabbri LM, et al. Mechanisms of occupational asthma. J Allergy Clin Immunol 2009; 123: 531-542.

27 Rijnkels JM, Smid T, Van den Aker EC, et al. Prevention of workrelated airway allergies; summary of the advice from the Health Council of the Netherlands. Allergy 2008; 63: 1593-1596.

28 Baur X. I are we closer to developing threshold limit values for allergens in the workplace? Ann Allergy Asthma Immunol 2003; 90: 11-18.

29 Bello D, Herrick CA, Smith TJ, et al. Skin exposure to isocyanates: reasons for concern. Environ Health Perspect 2007; 115: 328-335.

30 Vanoirbeek JA, Tarkowski M, Vanhooren HM, et al. Validation of a mouse model of chemical-induced asthma using trimellitic anhydride, a respiratory sensitizer, and dinitrochlorobenzene, a dermal sensitizer. J Allergy Clin Immunol 2006; 117: 1090-1097.
31 Heederik D, Henneberger PK, Redlich CA. Primary prevention: exposure reduction, skin exposure and respiratory protection. Eur Respir Rev 2012; 21: 112-124.

32 Arrandale VH, Liss GM, Tarlo SM, et al. Occupational contact allergens: are they also associated with occupational asthma? Am J Ind Med 2012; 55: 353-360.

33 Fishwick D, Curran AD. Variability in the diagnosis of occupational asthma and implications for clinical practice. Curr Opin Allergy Clin Immunol 2008; 8: 140-144.

34 Santos MS, Jung H, Peyrovi J, et al. Occupational asthma and work-exacerbated asthma: factors associated with time to diagnostic steps. Chest 2007; 131: 1768-1775.

35 Sauni R, Kauppi P, Helaskoski E, et al. Audit of quality of diagnostic procedures for occupational asthma. Occup Med (Lond) 2009; 59: 230-236.

36 Cegolon L, Lange JH, Mastrangelo G. The Primary Care Practitioner and the diagnosis of occupational diseases. BMC Public Health 2010; 10: 405.

37 Mazurek JM, Schleiff PL. Physician recognition of work-related asthma among US farm operators. Fam Med 2010; 42: 408-413.

38 Dykewicz MS. Occupational asthma: current concepts in pathogenesis, diagnosis, and management. J Allergy Clin Immunol 2009; 123: 519-528.

39 Cockcroft DW, Davis BE. Diagnostic and therapeutic value of airway challenges in asthma. Curr Allergy Asthma Rep 2009; 9: 247-253.

40 Health and Safety Executive. Asthmagen? Critical assessments of the evidence for agents implicated in occupational asthma. 2001. Available from: www.hse.gov.uk/asthma/asthmagen.pdf

41 Isola D, Kimber I, Sarlo K, et al. Chemical respiratory allergy and occupational asthma: what are the key areas of uncertainty? J Appl Toxicol 2008; 28: 249-253.

42 Kimber I, Basketter DA, Dearman RJ. Chemical allergens - what are the issues? Toxicology 2010; 268: 139-142.

43 Selgrade MK, Lemanske RF Jr, Gilmour MI, et al. Induction of asthma and the environment: what we know and need to know. Environ Health Perspect 2006; 114: 615-619.

44 Tarlo SM. Prevention of occupational asthma in Ontario. Can J Physiol Pharmacol 2007; 85: 167-172.

45 de Groene GJ, Pal TM, Beach J, et al. Workplace interventions for treatment of occupational asthma: a Cochrane systematic review. Occup Environ Med 2012; 69: 373-374.

46 Kristensen TS. Intervention studies in occupational epidemiology. Occup Environ Med 2005; 62: 205-210.

47 Vandenplas O, Dressel H, Nowak D, et al. What is the optimal management option for occupational asthma? Eur Respir Rev 2012; 21: $97-104$.

48 Talini D, Novelli F, Bacci E, et al. Comparison between airway responses to high versus low molecular weight compounds in occupational asthma. J Allergy (Cairo) 2011; 2011: 781470.

49 Labrecque M. Irritant-induced asthma. Curr Opin Allergy Clin Immunol 2012; 12: 140-144.

50 Quirce S, Barranco P. Cleaning agents and asthma. J Investig Allergol Clin Immunol 2010; 20: 542-550.

51 Burge PS, Moore VC, Robertson AS. Sensitization and irritantinduced occupational asthma with latency are clinically indistinguishable. Occup Med (Lond) 2012; 62: 129-133.

52 Fisseler-Eckhoff A, Bartsch H, Zinsky R, et al. Environmental isocyanate-induced asthma: morphologic and pathogenetic aspects of an increasing occupational disease. Int J Environ Res Public Health 2011; 8: 3672-3687. 